\title{
Everyday Uncertainty Work: Making Sense of Biosynthetic Menthol
}

\author{
ROBERT MECKIN ${ }^{1}$ \\ UNIVERSITY OF MANCHESTER \\ ANDREW BALMER 2 \\ UNIVERSITY OF MANCHESTER
}

\begin{abstract}
Although much public engagement with the field of "synthetic biology" has been conducted, there remains little work that develops an appreciation of how people make sense of this field and its concomitant promised futures from within their everyday lives. Using a case study, based on the compound "menthol" (a terpenoid from plants) which synthetic biologists have developed for production in E. coli, we explore how people make sense of uncertainties in promised or feared futures. Menthol is already an ingredient in many consumer products and the pre-existing use of such products may frame people's everyday techniques for understanding biosynthetic menthol, with implications for their appreciation of synthetic biology more generally. We adopted a range of sensory methods, including "pop-up" stalls, sketch research, object elicitation interviews and home tours, to explore the everyday situations in which menthol already figures. Participants used a range of strategies, including deferring judgment, invoking other actors as mediators, using their own bodily experiences and using existing moral repertoires, to respond to biosynthetic possibilities. We deploy the concept of "everyday uncertainty work" and show that it is a useful one for understanding how people's everyday epistemic cultures of uncertainty are routinely adapted to the anticipation of sociotechnical uncertainties, such as those that accompany promissory accounts of science. The implications for these findings for public engagement with technoscience and uncertainty are discussed.
\end{abstract}

\section{Keywords}

synthetic biology; uncertainty; everyday life; public understanding; science communication; sensory methods; creative methods

Robert Meckin, Email: robert.meckin@manchester.ac.uk

. Andrew Balmer, Email: andrew.balmer@manchester.ac.uk 


\section{Introduction}

There is a wide variety of public participation and engagement concerning synthetic biology (Pallet 2017). There have also been high level events, including the UK's "Synthetic Biology Dialogue," funded by the Biotechnology and Biological Sciences Research Council (BBSRC), which consisted of a series of workshops and stakeholder interviews exploring the issues of the science, its technical applications and its governance (Bhattachary et al. 2010). Although there are thus clear efforts to engage, scientists invested in synthetic biology tend to construct "the public" as a threat to their success. This is a problematic starting point for substantive engagement, for scientists fearing public fear leads to what Marris (2015) calls "synbiophobiaphobia." This anticipation of public rejection has been a key force supporting the upstream integration of social scientists within synthetic biology research groups (Balmer et al. 2015), visible, for example, in the 2012 report, "A Synthetic Biology Roadmap for the UK," ${ }^{3}$ which helped secure a place for social science within RCUK's six "synthetic biology research centers" (SBRCs). Social scientists have thus been positioned as interpreters of public attitudes, with the often explicit expectation that their presence within collaborations will engender greater public support.

As two sociologists working in a small team of social scientists within an SBRC, we have conducted research alongside science and engineering colleagues who are using synthetic biology techniques. The engineers and scientists aim to develop novel microorganisms capable of producing existing or entirely new chemicals. We have used this position to develop a richer approach to public engagement, which situates understandings of synthetic biology within people's everyday lives, aiming not only to challenge synthetic biologists' synbiophobiaphobia, but also to contribute to developing work in this vein within science and technology studies (STS) and public understanding of science (PUS).

An early emphasis of our SBRC's laboratory work has been to develop a metabolic pathway that converts the monoterpene pulegone into a range of derivative chemicals which function as important flavors and fragrances in a vast number of consumer products. The first derivative the team selected to work towards was menthol, an essential component of mint flavor (Toogood et al. 2015). Minty flavors and fragrances, in what market analysts call fast-moving consumer goods (FMCGs), often include menthol as an ingredient, meaning it can be found in many everyday items, such as toothpaste, confectionery, cold remedies, chewing gum, shower gel and muscle rub. This has made menthol a large segment of the global mint oil market, which is about 30000 tons per year (Lawrence 2007). Menthol, therefore, also became our target substance for sociological investigation.

At present, the production of menthol occurs through one of two processes: 1) agricultural, via the cultivation and subsequent treatment of mint plant leaves to extract menthol; 2) chemical, via one of several possible chemical synthesis routes, each of which is used by a different company (Rao 2015). Our colleagues in the SBRC constructed a biosynthetic route to

${ }^{3}$ http: / / www.rcuk.ac.uk/documents / publications / syntheticbiologyroadmap-pdf /

"Research Councils United Kingdom 
production by engineering E. coli using synthetic biology techniques. At the same time, they developed a sociotechnical promissory account of a future in which "biosynthetic menthol" was manufactured on an industrial scale, enabling a third global supply option. The hopes embedded in this account were for this compound to be cheaper and more sustainable than agricultural or chemical processes. The literatures regarding such sociotechnical expectations have described the creation, management, and performativity of promises regarding the future (Borup et al. 2006; Brown and Kraft 2006; Brown and Michael 2003; Wainwright et al. 2006). It was clearly the case that promised futures for synthetic biology and, in our Centre, for flavors and fragrances in particular, structured our colleagues' work. But they also anticipated potential economic and ethical problems, since current agricultural production is largely carried out in developing countries, with India being the largest producer, meaning a change in menthol markets might have significant impacts on poorer farmers' livelihoods. Both the nature of the biosynthetic menthol (that it would be produced by genetically engineered E. coli) and its sociotechnical context (economic, environmental and ethical issues) meant that the engineers and biologists we worked with were already sensitized to the possible rejection of their innovation due to public concerns in these and possibly other areas. A central issue at stake, therefore, was sociotechnical uncertainty: what consequences might emanate from such an innovation? would it be demonstrably cheaper, more sustainable, economically-viable, ethical and responsible? how might people respond to this innovation? would people see biosynthetic menthol as "unnatural"? would the production method be accepted over alternative routes?

To investigate these issues we adopted a range of sensory methods, including "pop-up" stalls, sketch research, object elicitation interviews and home tours, to better understand how people might make sense of these uncertainties in a promised future, from within the everyday situations in which menthol already figures. This paper argues that in everyday life there are epistemic cultures of uncertainty woven into mundane practices of parenting, health and illness, hygiene and personal care. We show that the concept of "uncertainty work" is a useful one for understanding how it is that people's everyday epistemic cultures of uncertainty are adapted to the anticipation of sociotechnical uncertainties, such as those that accompany promissory accounts of science. We use the case study of biosynthetic menthol to develop this approach, evidencing four strategies which frequently appeared as part of people's everyday uncertainty work: 1) reasoning and deferral; 2) drawing on embodied experience; 3) using moral repertoires; and 4) deference and mediation. We conclude that these findings have wider significance, not only regarding everyday understandings of other biosynthetic consumer products, but also of the ways in which people make sense of and manage uncertainties in promised sociotechnical futures more broadly.

\section{Understanding Sociotechnical Uncertainties}

Uncertainty has long been and remains a key theme in STS. Early studies evidenced uncertainty in laboratory work, classification schemes and diagnosis of medical disorders, showing that much effort goes into the analysis, resolution and management of uncertainty within science and 
medicine (Fox 1957, 2001; Star 1985; Daston and Galison 1992; Shackley and Wynne 1996; Timmermans et al. 2001). Since many uncertainties cannot easily (or perhaps ever) be resolved, they also become key components in the production and governance of sociotechnical controversies (Wynne 1992; Levidow 2001; Callon et al. 2009). Uncertainty thus also figures powerfully in the coproduction of science, law and social order more broadly (Lynch 1998; Jasanoff 2011). When coupled to the increasing prominence of technology in the conduct of everyday life this has led some analysts to claim that we now live in an age of uncertainty (Nowotny, Scott and Gibbons 2001: 202): "Many aspects of life once taken for granted, whether as continuity or change, are now matters of decision. The future, of course, is more uncertain than ever because it depends upon the decisions of many others." This is also readily seen in the ongoing politicization of uncertainty in the governance of sociotechnical innovation (Braun and Kropp 2010).

In their review of the literature, Powell et al. (2007) argue that the majority of research on uncertainty (outside of the social sciences, at least) understands "uncertainty only as an "objective" state of the world "out there"--a state most accurately defined by scientists" and find that this reifies a deficit model of public understanding, constraining what can be discerned of people's ways of dealing with sociotechnical uncertainties. Within the weft and warp of this literature, however, sociological threads depict the ways in which people make sense of uncertainties in science within the context of public engagement activities, public dialogue or consultation processes, and (less notably) within the day-to-day negotiation of sociotechnical systems.

Some of this work concerns cases of pertinence, for instance, by its reference to the life sciences, biotechnology or environmental studies. Uncertainty has been, for example, at the heart of controversy over, advocacy for and resistance to genetically modified (GM) crops and food (Levidow 1999) and continues to be a powerful feature of contestation regarding climate change (Ryhhaug et al. 2011). Much research seeking to understand how everyday people make sense of biotechnology and related fields, including synthetic biology, has--at least in more recent years-tended to focus on the media's role in these processes. These studies have variously found that journalists do or do not emphasize uncertainty in their presentation of scientific issues, depending--it seems-on the particular scientific field being reported on (see, for a review: Rurhman et al. 2015). There are also differences in how professionals of various sorts and "the general public" use the terms "risk," "uncertainty" and so forth, as Collins and Nerlich (2016) show with regard to climate change. Where research has been concerned more directly with how people interpret media constructions of uncertainty it has found that everyday phenomena might play a prominent role (Ryhhaug et al. 2011: 788): "the domestication of climate change knowledge for some may be slow or difficult, not because the knowledge is difficult to understand but because it may be dissonant with the established practices of everyday life." Indeed, when people make sense of GM crops and foods they create a "bricolage" of reasoning drawing on many resources (Horlick-Jones et al. 2008). However, even here there is very little situated engagement with people's everyday practices as a resource for making sense of uncertainty. 
It is clear that the mass media does play an important role, especially since political decision makers are now regularly faced with mass-mediated scientific expertise (Petersen et al. 2010). But it is important to note that such accounts of media effects on policy makers and other publics remain divorced from the everyday situations and practices where sociotechnical innovation becomes "live" for people. As Wynne (1992: 40) argued some time ago, "social positioning work, or social identity-maintenance and repair, is the fundamental dimension within which scientific knowledge is experienced and received, rejected, [and] reshaped." But this remains to be clearly articulated, at least in the context of synthetic biology, with regard to how people do such work within their richly-populated relational worlds of objects, people, norms, practices, roles, and so on. Understanding the ways in which local phenomena shape people's ways of making sense of sociotechnical uncertainties requires further study, which our paper aims to develop and open-up by engaging with sensory methods better equipped to work within such everyday settings.

Towards the development of such an approach, we draw on Böschen et al. (2010) who argue that there are different and potentially competing epistemic cultures of uncertaintys. This is a foundation stone for our analysis, for our findings indicate that people do indeed draw upon situated methods for making sense of unknowns, uncertainties, their own ignorance and other non-knowledges. Moreover, such everyday epistemic cultures of uncertainty are not simply a given by virtue of participant's subject positions (as "non-experts," "teachers," "women" and so on). These are important, but these positions are invoked as part of relational and situated interaction regarding uncertainty. Claims to ignorance or certainty, ways of identifying or coping with uncertainty, are worked-up through talk, which is sensitive to the norms and values accompanying the practices in which people are routinely engaged. Where menthol figures as part of everyday life, we argue, informs how people respond to uncertainty when it comes to biosynthetic futures.

In this regard, the concept of "uncertainty work" is of value. Although they do not invoke the term themselves, Shackley and Wynne (1996) identify the ways in which claims to uncertainty are produced, silenced or managed as boundary ordering devices to organize (and sometimes cross) the lines between science, policy, publics and so on. Moreira et al. (2009) deploy the term "uncertainty work" to refer specifically to the ways in which scientific actors and practices are arranged to close-down or open-up such uncertainties, but also more mundane uncertainties within epistemic work itself, in strategic and sometimes reflexive ways. Building on these insights, Pickersgill (2011) adopts the term to show how uncertainty work is not only a part of reflexive moments or periods of contestation in science, but a mundane and practical part of maintaining orderliness and allowing research to continue in the face of such uncertainties. In this paper we adopt the concept of uncertainty work to better articulate how people engage with mundane epistemic cultures of uncertainty within their situated and routine practices of care,

s Or what they term "non-knowledge," a broader term than uncertainty, which might include related phenomena such as "ignorance" and so forth. 
parenting, hygiene, and so forth, and bring these to bear on anticipating futures of biosynthetic menthol, with broader ramifications for public understanding of science.

\section{Case and Methods}

As part of their everyday lives, people engage with a vast array of technologies in mundane ways (Marres and Lezaun 2011; Marres 2015; Davies 2018). The SBRC's identification of menthol as a target for biomanufacturing offered us a way into exploring how people could deal with sociotechnical uncertainties because menthol is already incorporated into everyday products, and used in a range of mundane activities, such as tooth-brushing, alleviating symptoms of illness, showering and so on. We developed a methodology that would prioritize the "lived" experiences of menthol in practice, and use these discussions to propose to participants an imagined future where such products could include menthol made via a biosynthetic route. The idea was to embed elicitation regarding the future, in the routines and repertoires of everyday life. We therefore hoped to address some of the limitations of engagement processes (like workshops and surveys), which include a tendency to privilege linguistic reasoning over embodied, aesthetic and affective deliberation (Selin et al. 2017), and to isolate everyday life by staging public engagement events in unfamiliar situations (Bogner 2012). We develop these methodological points and reflections more substantively elsewhere.

A peculiarity of menthol is that the human body can distinguish the cooling sensation and minty taste even when menthol is mixed with other flavors, salts and stabilizing chemicals found in products like chewing gums, shower gels and sweets. For us, sensory stimulation provided a way for participants to respond to taste, feeling, odor and appearance of mentholated products and allowed us to start conversations about experiences, memories and practices. To this end, we had two shopping bags of menthol-containing products that we carried around to various sites of engagement and that we used as ethnographic material "probes" (Michael 2012; DeLeon \& Cohen 2005; Woodward 2016). We trialed sensory elicitation in different contexts and with different group sizes. We conducted seven object elicitation interviews, nine home tours in which participants guided us around their homes and showed us where and how they used menthol products (see figure 1), two focus groups using object elicitation (see figure 3) and five "pop up" stalls, which consisted of a table of products set up in a public place (see figure 2). We were able to organize the pop up stalls in different locations: a museum, a department open day, a large shopping center, a garden center and a university "taster" day for school students. We engaged passers-by and, following our exchange, asked them to fill out postcards, which were later transcribed.

Once we had begun the conversations about people's experiences and practices, which tended to be longer and more expansive in the interviews and home tours than pop up stalls, we introduced the idea of biosynthetic menthol and, along with explanatory photographs, the possible consequences of shifting to biomanufacturing. First, we reported how our colleagues hoped that biosynthetic menthol would be more environmentally sustainable because cropland currently used to cultivate Mentha arvensis (cornmint) could be used for other plants, such as food 
crops, and would be more efficient and profitable than conventional agricultural production (in the longer exchanges we spoke also of synthetic chemical methods). Second, we explained that scientists were also aware of the potential effects on farming communities, particularly those that rely on Mentha arvensis cultivation in India and China. Our data consisted of field notes, interview and focus group transcripts, photographs, videos, and illustrations by an artistcollaborator, Lynne Chapman. ${ }^{\text {The }}$ The were imported into NVIVO and systematically and iteratively coded by the two authors in a process of analytic induction (Bloor 1978; Silverman 2014). This indicated participants used a range of strategies to make sense of future prospects for biosynthetic menthol through different kinds of uncertainty work, which we report below. Where relevant, we also bring out differences in uncertainty work based on the different methods we deployed.

\section{Everyday Strategies for Making Sense of Sociotechnical Uncertainties}

In our analysis of the data we found four related but different strategies that our participants used in making sense of a possible future in which biosynthetic menthol became an ingredient in consumer goods. These strategies were used by participants to negotiate different kinds of uncertainties in the science, economic context, commercialization and ethics of biosynthetic menthol. The four strategies of uncertainty work that we present are:

1. Reasoning and deferral - participants used everyday forms of reasoning about science, economics, consumption and so forth, to negotiate uncertainties regarding the future and regarding the motivations of scientists and industrialists, oftentimes deferring their judgment to a time at which more might be known.

2. Drawing on embodied experience - some participants drew on their existing embodied experiences, for example of using consumer goods or medicines, to make sense of the novelty of biosynthetic menthol by relating it to things which are better understood and more mundane.

3. Using moral repertoires - participants used everyday, situated notions of what is "good" and "bad," notions which are applied routinely in their everyday lives, to make sense of the moral uncertainties implied by the production and consumption of biosynthetic menthol, when compared with existing production and use of mint-derived menthol.

4. Deference and mediation - participants invoked other actors (e.g. scientists, brands, companies, organizations, imagined groups, relatives or friends) to mediate all kinds of uncertainties in the production and consumption of biosynthetic menthol and referred responsibilities on to these agents.

'https://www.lynnechapman.net 


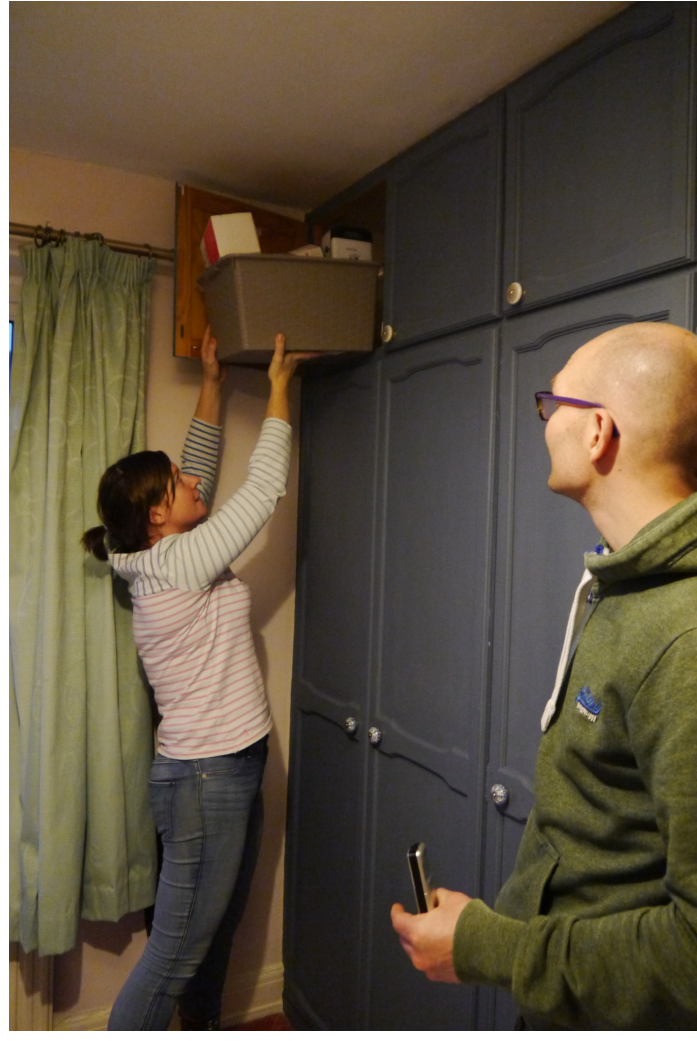

Figure 1: A participant lifts down a medicine box during a home tour

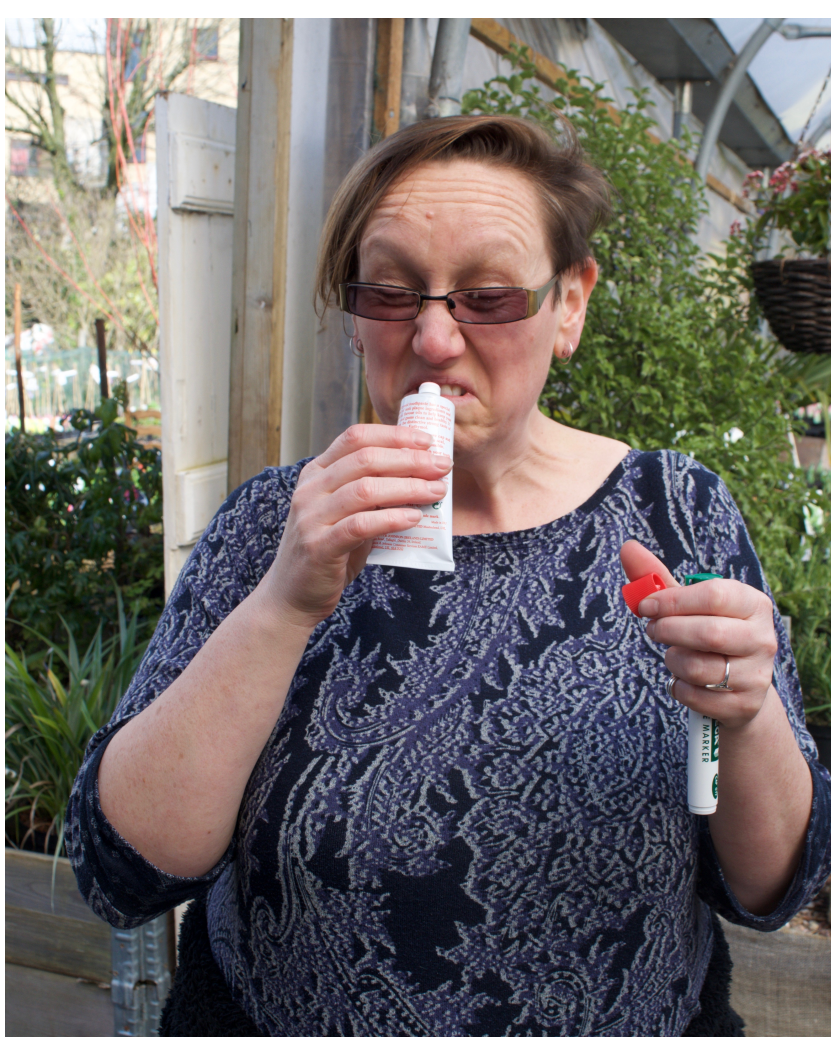

Figure 2: A participant wrinkles her nose smelling toothpaste in a garden center

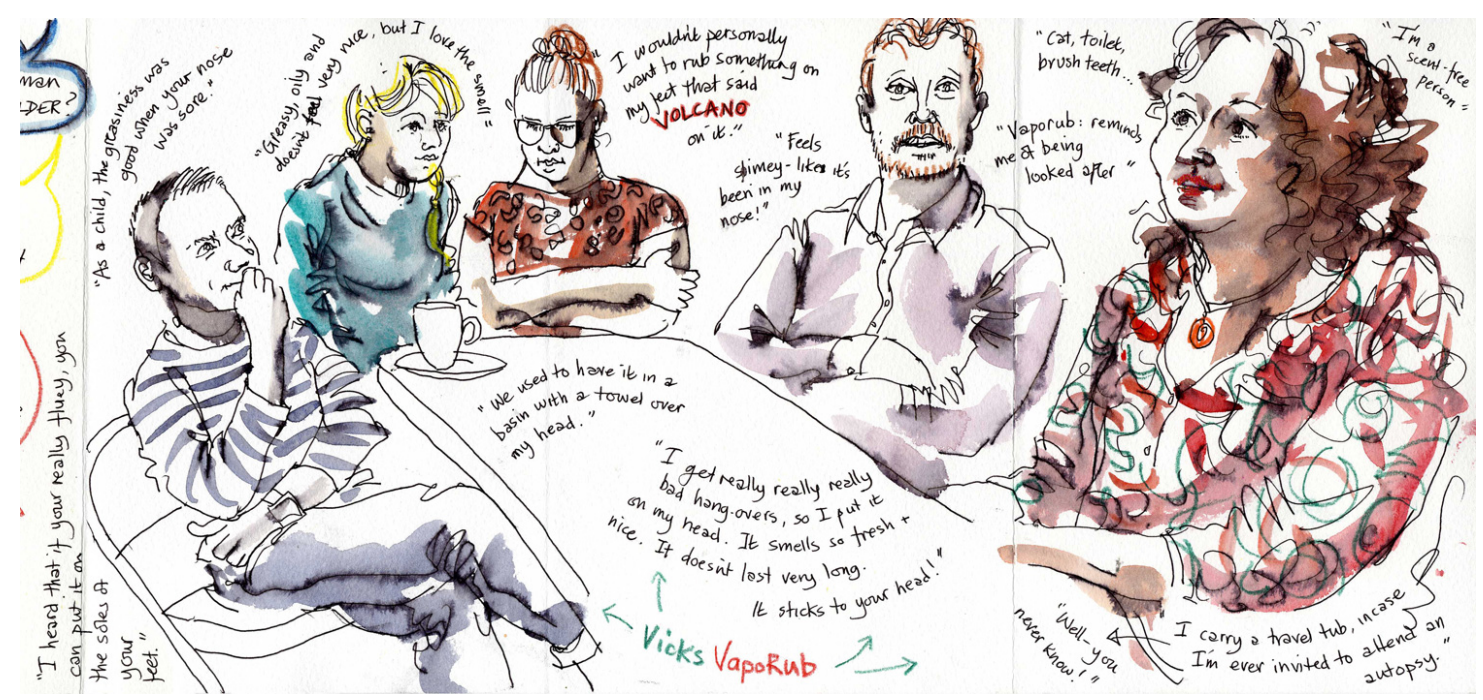

Figure 3: A sketch of a focus group. Copyright held by Lynne Chapman. 
In what follows, we explain these strategies in more detail, evidencing them with quotations from our participants' talk and demonstrate some of the ways in which these strategies linked together. The conclusion that we reach regarding these strategies is that they are connected to the everyday management of unknowns, things that are unfamiliar, and to the anticipation of a future which is uncertain. They should not be understood to reflect all the ways in which people might anticipate and make sense of a future in which biosynthetic menthol figures, but based on our data they are likely to play a prominent role. At the same time, they show the diversity of ways in which people orient to uncertainties in science and innovation, evidencing their conduct of situated, local, everyday uncertainty work.

\section{Reasoning and Deferral}

Our participants engaged in everyday reasoning about science, based on their existing knowledge, experience, and on the information we provided, or which they had collected independently in preparation for their engagement with us. A key part of much of this reasoning involved deferring judgment or decision-making until more is known about biosynthetic menthol, or until the product becomes "mundane" through widespread application. It is in this regard that reasoning and deferral were linked to the management of uncertainties in people's engagement with science and technology, but also in the future.

In the following quotation from Mike, a father of two and keen reader of popular science books, who had left university without his engineering degree and was now pursuing a successful career in finance, we can see how he reasons from his knowledge about the use of mint plants as a source of menthol. He makes an explicit connection between the past and the future with regard to the uncertainty implied by the development of a new method for making menthol.

Mike: I think the mint plant has been used, even if it has not been scientifically tested, but it has been tested by people using it for hundreds of years or more. Like, menthol or mint must have been used in various cultures for a long time. So, there's been a long, long time for the bad things to have come out a lot more. Whereas with synthetic biology, it's brand new ... There's a lot more to know, more that could go wrong. (Mike, 35, home tour 3)

This quotation exemplifies the way in which participants generally oriented to the uncertain future by considering the past (see Adam and Groves 2007). Since mint plants have been used to produce menthol--or have been used directly--in food, drinks and medicines, Mike reasons that they can be given more confidence when compared to the new and potentially unpredictable use of biosynthetic menthol for the same purposes. This links to an interpretative dilemma regarding scientific innovation and uncertainty in everyday accounts, as Böschen et al. (2010: 786) identify:

When we find, for instance, no empirical facts indicating harmful effects of a certain GM plant, this situation can be evaluated in two contradictory, yet equally reasonable ways: 
either in terms of reliable knowledge that there actually are no harmful consequences or in terms of possible unknown unknowns-which means that we are unsuspecting where, when, and how hitherto unforeseen effects might occur.

Mike, then, leans towards the first option in considering existing menthol as having reliable knowledge and the second option for evaluating biosynthetic menthol as harboring unknown unknowns. This is a kind of everyday uncertainty work, to the extent that comparative reasoning between what exists and is understood and what is anticipated and unknown helps Mike to highlight uncertainties in synthetic biology and thereby justify caution in its adoption. What is new, Mike reasons, is more uncertain and thereby more threatening because the price for things that go wrong will be paid by those alive today, rather than those who - in this example saw the introduction of mint plants to our diet, or menthol to medicines, in the past. Why, implies Mike, would he take on a risk when there is a perfectly satisfactory and well-known alternative?

There was plenty of diversity in reasoning, most especially we found this in our pop-up stalls data, which collected a greater number of responses. Here, however, participants drew more superficially on the information we had presented to them about how synthetic biology worked and regarding its potential implications (for sustainability and developing economies). Here it became clear that uncertainty was not always problematic, for example, as two students at a laboratory open day put it:

Everything has an uncertainty. Why would having menthol produced by bacteria be a problem if it's more environmentally friendly and sustainable. (Female, 17, dept. open day)

It's a good idea to make menthol this way as it's more sustainable. I'm not put off by the fact it comes from bacteria. (Female, 17, dept. open day)

Both of these brief comments argue that when weighed-up, the promise of sustainability outweighs any concerns about bacteria or different forms of uncertainty. In contrast, some participants weighed things up and then emphasized scientific and economic uncertainties, for example in the two pop-up comments below:

I have concerns about employment in India/China, export + knock-on development impacts. (Male, 46, shopping center)

Patenting is an issue and potential for gene/bacteria escape. (No participant details, garden center)

Participants' reasoning in the pop-ups was far more influenced by the scientific content and context we presented since their interactions with our menthol products were in settings more familiar to public consultation and education. Some of the pop ups were, for example, 
hosted in educational environments (e.g. a museum) or commercial locations (e.g. a garden center), which are public spaces where mundane uses of menthol tend not to figure prominently and where other modes of interaction coproduced roles which participants comfortably inhabited (e.g. being a student, or being a consumer). The illustration (figure 4) captures the interactive bustle as participants at the pop ups used and discussed menthol. This contrasted with the modes of interaction that we observed when encountering people in the spaces in which they more usually used menthol products.
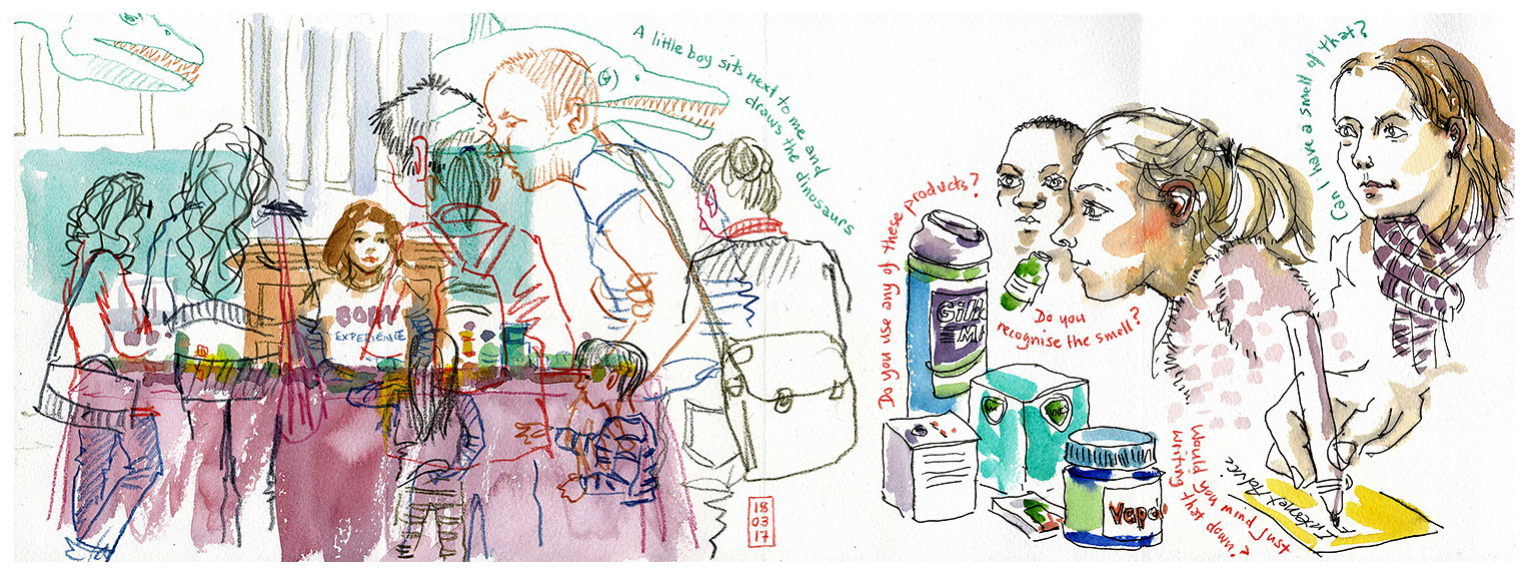

Figure 4: Various people and activities: A sketch of a pop up stall by Lynne Chapman. Copyright held by Lynne Chapman.

As such, in the longer, situated, more engaged encounters we had, in home tours and object elicitation interviews, other forms of managing uncertainties became available and in these spaces deferral was often the outcome of reasoning about science and the future. Home tour and object elicitation participants less readily concluded one way or the other, and often deferred on the issues regarding biosynthetic menthol, by which we mean they suspended their judgment on whether they think it is right to make it, whether they would use it, and so on, to a time at which uncertainties have been reduced, or when more is known. This indicates that in different kinds of engagements, different kinds of responses are produced. More fleeting encounters favor decisiveness and reproduction of technical information, whereas longer encounters allow for uncertainties to be mulled-over and held in place, interpreted through the routines in which people are more usually engaged.

In the data, deferral until more is known was sometimes applied to other actors, such as when participants argued that scientists needed to know more about what they were doing before commercialization took place. But it was also a position participants took themselves, indicating that they wanted to know more about the issues at stake before they could make a decision. The example below, from a home tour with Helen, a media and culture university lecturer, shows that participants sometimes had questions they would like answered, things they'd like to know, before they could really come to a conclusion regarding how to act. 
Everyday reasoning about possible futures of science, innovation and consumption is informed by what people already know about these issues from other parts of their life. Helen's response to the researcher's question, for example, draws on her experience as a vegan:

Researcher: If these products [indicating the consumer goods on the table] contained menthol made by microbes, would that be ok to you?

Helen: It depends because there are all these things on eco stuff now. They were testing things [consumer products] on water fleas, like microbial lice. Even though they are kind of small, and people eat yeast and stuff like that, because it was kind of small forms of what was seen as an animal--it still counted as animal life, even though you could not see a water flea, the Vegan Society classed that as not vegan. But they are testing it for an environmental reason, so I feel for me that is a really grey area, because it's like the environmental impact of things is so important to sustain and I don't feel like I know enough about what is happening with that to make a proper judgment about it, really. I suppose I would question the need for [biosynthetic menthol] in some ways. What's the motivation? What is it tied to? What sort of interests are behind that? ... How they would get into the market and how it would be tested; the kind of socio-economic configurations and what sort of infrastructures and scales [of food production] would it change and what is it replacing.? What are the politics of it? (Helen, mid-30s, home tour 5)

In the quotation, Helen reports a recent case in which the Vegan Society had chosen not to give some consumer products vegan status because they had been tested on microscopic animal species. But this testing, she explains, was done in order to check if the products were more sustainable and had any negative, environmental impacts. Helen is presented with a difficult issue here, because she both wants to eat a vegan diet and live a vegan lifestyle, but she also wants for more sustainable, environmentally-friendly products to succeed in the market. As Helen tastes and touches menthol products from around her house (and some of those we brought with us) an uncertainty in how to judge the political or ethical implications of consumer goods in this other context of her life is applied to the prospect of producing biosynthetic menthol. Based on the information we provided about the two key rhetorical promises of synthetic biology in this case, Helen draws attention to the competing environmental versus economic imperatives that are difficult to resolve. She makes sense of these through the lens of uncertainties both in science and innovation: "how would it be tested?," "what would it change?," "what would it replace?" and so on. Although Helen implicitly assumed that there was a scientific motivation behind the work which would be a fair and just one, she also did not take this on faith alone, nor based on the scientists' hopes which we presented to her. Her conclusion is that we (and she) need(s) to know more about the science, about the innovation process, its environmental effects, and so on, before making a decision on whether biosynthetic menthol represents an ethical (and for her a vegan) consumer good, or not.

When connected together, as they frequently were in participant's talk, everyday reasoning and deferral served to maintain uncertainties, holding them in place as part of a considered response. Participants contextualized uncertainties by use of familiar forms of 
reasoning and judgment, for example regarding weighing up relative risks (as Mike spoke of the difference between mint plants and menthol), using existing ways of judging science (as Helen did in drawing on veganism and environmentalism) and in linking quite abstract promises about the future and broad uncertainties in science and innovation to particular actors, i.e. to the scientists actually conducting the work, or the industrialists that may profit from it. In negotiating uncertainties regarding the future, participants established a plurality of possible responses they might have and developed questions they wanted answered, allowing them to avoid committing to a particular judgment or position. This form of everyday uncertainty work shows the sensitivity that participants have to possible perspectives on science and innovation when trying to make sense of the future, demonstrating their openness to informed dialogue that takes into consideration their situated, everyday concerns.

\section{Drawing on Bodily Experience}

The human body was deployed as a resource in apprehending a biosynthetic future. Sometimes participants used a generalized concept and sometimes their own somatic experiences. For example:

Mike: I think I like the idea of things that have been more naturally produced and things that are more natural in the world in that because we as a species have evolved to adapt to the real world that we live in and when we start synthesizing and we are adapting the world we live in to suit us when we don't actually fully understand ourselves and, therefore, there is inherently risk in that. There is inherently risk when you are starting to create a world, adapting the world to our bodies when we don't fully understand our bodies, we don't really know what we are letting ourselves in for and that's just an ethos that goes throughout really. (Mike, 35, home tour 3)

In his comments above, Mike argues that risks in science and innovation might be amplified by uncertainties in how our bodies work or how they respond to different chemicals. This position is in keeping with the quotation from Mike in the previous section, in which he argues that things that have been established for human consumption for thousands of years are more trustworthy than new consumer goods. In this way, he implicitly invoked an idea of embodied certainty, a kind of trust in the human body as an indictor of safety developed through human history.

Trusting things that were familiar was a regular finding in the data, but how this was articulated differed based on participant's particular embodied histories. For example, in the following exchange, Benny drew on a more immediate bodily experience as he situated our question about checking ingredients on products he buys within the context of a variety of medicines he already takes by virtue of having diabetes.

Researcher: Does it matter to you where the ingredients come from--where they are made? 
Benny: No I have a sort of firm belief if its more economical and more environmentally sound to create it in the lab then it should be-maybe again because of my diabetesinsulin is produced by E.coli in ridiculously large vats but without it I wouldn't be alive. So it's one of those things where it doesn't really bother me ... I would rather it came from a clean lab than--you know, wherever. (Benny, 18, object elicitation interview 2)

Here, Benny's history of treating his diabetes using microbially-produced insulin is linked to the sterile environments of hospitals and scientific laboratories. This existing embodied experience is deployed in his anticipation of biosynthetic menthol, rendering it both familiar and mundane. Although contrasting in their result, both Mike and Benny's responses spoke to a common theme, the way in which embodied experience was used to inform participant's understandings of uncertainties concerning biosynthetic products.

There was also a tension for most participants when considering competing understandings of relations between microorganisms and bodies. In everyday life, for example when cleaning the house, microbes are generally understood as a threat, and this is true in most people's professional lives as well, whether they're chefs, dentists or sewerage plant workers (Balmer and Molyneux-Hogson 2013). This understanding fits well with the practices of hygiene, caring for children, making dinner and so on. It is this conceptualization that sits most conformably alongside existing menthol products, for they are often to be found in products designed to help people cope with a cold, manage a cough or freshen their breath. The scientific case put forward an account of bacteria as being a safe, sustainable, efficient and economically advantageous way to produce menthol at some point in the future, but their everyday experience of bacteria was as the object of attack for those very products that scientists wanted to change. Here are a few examples of comment cards from pop-up stalls:

E-coli is well-known as a dangerous bacteria. Can I be sure it's safe? (Female, 44, Museum)

In the long-term would the bacteria affect any part of your body? (Male, 40, Museum).

If Tic-Tacs had bacteria people would think they could get disease. (Female, 13, University "taster" day)

Bacteria is bad-disease. (Male, 13, University "taster" day)

In these examples, we see that a range of participants developed this account, though again the depth of reasoning and connection to their everyday lives was more superficial, especially for younger participants. Nonetheless, even these snippets reflected the mundane way in which bacteria are understood through body, health and illness, aligning with ways that menthol is used as an ally in the products that help people fight against colds and flus, coughs and sneezes. 
One future narrative that circulates through the synthetic biology communities in the UK is that synthetic biology may suffer a similar public fate as genetically modified foods, which scientists imagine was rejected "by the general public." Our data, though, suggests a more nuanced relationship between the history of GM and synthetic biology is developing. For instance, the following quotation by Dani, a higher education administrator, shows how the body could be part of a larger network of resources that are used to make sense of synthetic biology:

I guess [biosynthetic menthol] is much like getting genetically modified crops-personally I feel that I have eaten a lot of foods stuff like this and I am still fine and my parents are fine and even my grandparents are-partially because in the world that we live in I feel like the issue isn't necessarily about one thing, it's about a bunch of nothings. If you are going to eat a lot of genetically modified products, but if you eat a range of thingsdiversity is what you should be doing-I am less worried about the effects of GM products I am more concerned about I guess things like the carbon footprint in things. (Dani, 33, object elicitation interview 3)

Dani draws on her own body and the bodies of her parents and grandparents to reason that GM crops, which she believes they have all consumed, are safe. Dani also draws on commonly-received advice that food intake should be varied, to imply that GM and non-GM foodstuffs could be part of a balanced diet mitigating any effects of GM foods. The outcome here is different to Helen's reasoning in the previous section because Dani implies that a biosynthetic future is compatible with her current practices and ways of living-she does not call for more knowledge. Furthermore, it is possible that, because she can use bodies to mitigate uncertainties surrounding future synthetic biology products, she cannot do the same for her worries about climate change effects of production. Ultimately, in Dani's argument, uncertainties regarding anthropogenic climate change supersede those of GM crops for they cannot be anchored in experience, and-perhaps-are out of her direct control.

These data suggest that individual bodies, the abstract "human body" and its history can be important sites in which uncertainties in the future are managed. Perhaps this is because individual's bodies were brought to the fore by the methods we used, having participants smell, taste, touch and so forth. Rather than biasing the results this was a key strength of our approach for it more readily connected their talk to their lived, embodied experiences of menthol consumer goods, existing experiences of health and illness, pharmaceuticals and so forth. This shows that uncertainties in novel technologies may be resolved, particularly where consumption is involved, by virtue of individual differences in embodied experience, both in construction of their banality or their riskiness. Since these are peculiar to individual's life histories, these modes of reasoning are unlikely to be changed on a collective level, by scientific communication of facts about bacteria, synthetic biology, and so on. 


\section{Using Moral Repertoires}

Linked to the competing accounts of bacteria as a threat or as part of a safe industrial process was a moral distinction, one which is perhaps a more recently established binary in everyday understanding, namely between "good bacteria" and "bad bacteria." This distinction seems to be a result of branding developed by companies producing consumer goods containing microorganisms, for example the well-known "Yakult" brand of probiotic fermented milk drinks, as well as contents of the previous national curriculum (Department for Education and Skills 2004, 24). Participants often invoked this distinction in trying to understand how to place biosynthetic menthol and make it meaningful within their existing set of concepts and practices. Various short comments from pop up stall participants invoked the distinction:

Is it friendly bacteria? (Female, 77, Museum)

Some bacterias can be bad. (Female, 9, Museum)

Some bacteria are good and some are not. (Male, 40, Museum)

It depends if it is a good bacteria or a bad bacteria. (Male, 11, University "taster" day)

The notion of good and bad bacteria extends the way in which bacteria are understood through embodied experiences of health and illness by classifying some bacteria as acceptable, under certain conditions. Recently, the idea of the "microbiome" has become more commonplace, and although this did not often come up in our data, it is likely that a shift in how bacteria are conceptualized is underway in everyday life, reflecting, perhaps, the way in which everyday conceptualizations of the immune system changed since the 1980s, away from a mechanistic or military model to a network or systemic model (Martin 1994). The effects this might have on the reception of synthetic biology and its applications are yet to be explored.

Such moral distinctions pervaded our participants' talk, especially in the more situated encounters that we had. It is clear in the data that these are deeply entwined with the practices in which people are routinely engaged as skilled social actors. We found that a common distinction made as part of practices of consumption, of caring for children and of family, in which menthol products regularly figure, was that of "natural" and "synthetic" (or "artificial"). This distinction is one that the synthetic biologists we work with had anticipated, partly because they already worry that the name for their field might in itself put people off biosynthetic products. For example, in the exchange below, Jen links the notion of "natural" menthol to her child caring responsibilities, to how she makes judgments on what she can trust as a parent, and how this figures as part of a broader negotiation of being a mother in contemporary British society:

Jen: I don't know if it matters in terms of is it the same thing if it is not grown, if it is not taken from plants, because to me something that comes from a plant I feel I trust it more than something that is made in a lab which is why I asked you really... if there was two products I would probably choose the one that had come from the plant... because I 
would primarily use it to put it on the children and I would feel, well I just felt we are bombarded by products and things, things like Diet coke and it is made with artificial sweeteners, so that is not good because it is artificial, and I think I have got something in my head which is saying anything artificially made is not good for you. (Jen, 33, home tour 3)

In this quotation, Jen explains why it matters where things come from. For her, she chooses menthol-containing vapor rub because of its "natural" connotations. In the context of caring for a child, claiming that something is "natural" is often a proxy for saying that something is "safe for children," "gentle" or "familiar." Jen draws on the cultural repertoire of parenting to make sense of uncertainties in synthetic biology and biosynthetic products. As Swidler (2001: 2425) argues, it is helpful to think of culture as:

a repertoire, like that of an actor, a musician or dancer. This image suggests that culture cultivates skills and habits in its users ... and that such cultured capacities may exist both as discrete skills, habits and orientation and, in larger assemblages, like the pieces a musician has mastered or the plays an actor has performed. It is in this sense that people have an array of cultural resources upon which they can draw.

To know that menthol had been produced in a different way would worry Jen about using vapor rub on her children because it troubles the norms embedded in the cultural repertoire of parenting, not because of a well developed technical explanation. Biosynthetic menthol asks her to trust something unfamiliar when a familiar alternative is readily available, meaning that she is asked to take a risk in how she cares for her children. Indeed, even as she implies her own ignorance of the chemistry, as she says "I don't know if it matters... if it is the same thing," she also makes clear that this is not the issue, since her judgment is not concerned with materiality, so much as it is with the moral status of her parental choices. While it is possible to classify menthol molecules as the same chemical thing no matter the source, it becomes a demonstrably responsible choice as a parent to prefer a plant-derived menthol molecule to a bacterial one by virtue of the practices in which the molecule "menthol" takes on its properties. In other words, a menthol product is more trustworthy if the source is "natural" not because of a scientific definition but because "natural" emerges in relation to other concerns in specific social contexts

This kind of reasoning is not necessarily a product of ignorance of particular distinctions or scientific values, but of different purposes. A further example clarifies this. One of our participants, Gabby, 34, a mother of two and holder of a degree in Chemical Engineering, had changed career shortly after attending university and retrained as a therapist. She was also someone who regularly used menthol and minty products in her everyday life. She carried multiple products in various pockets of her handbag (see figure 5), and freshened her "coffee breath" with chewing gum during her commute to her job working with children with disabilities (see figure 6). 


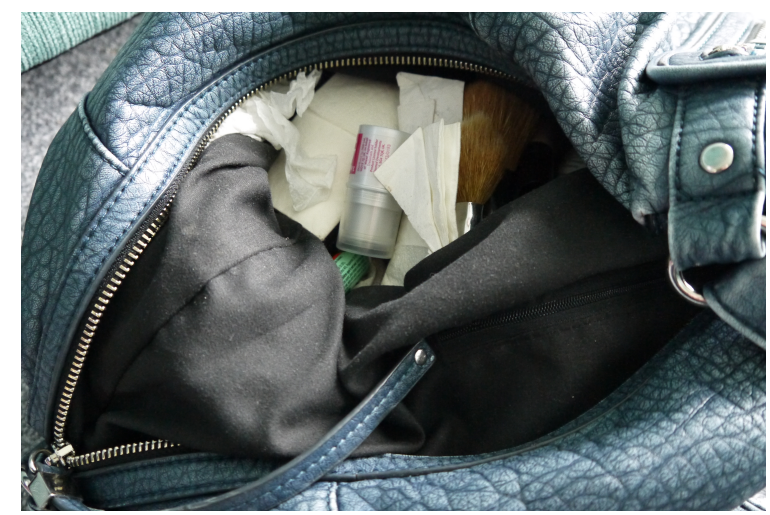

Figure 5: A headache soothing stick and a nasal inhaler (just visible) among the folds and tissues in Gabby's handbag

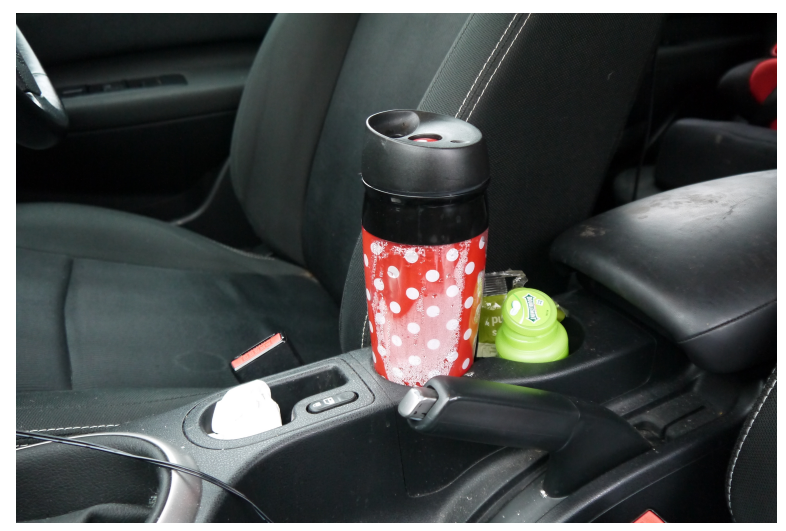

Figure 6: Cup holder with coffee travel mug and mint pot in Gabby's car

Gabby's disposition towards synthetic biology was partly informed by her scientific training (she had some degree of understanding of what it might mean to synthesise menthol in a laboratory and in an industrial plant) but was mostly negotiated through recourse to other values and concerns. Like Jen, she talked of plant-derived menthol as being "natural" and described the process that she goes through in shopping for products, how she was attentive to the different age ranges ascribed to different medicines, that she is guided by the product labeling and where they are merchandised on the shop shelf, emphasizing how she continues to buy products from a physical store rather than online, so she can be more sure she is purchasing something in which she can have confidence. It is possible to think of Gabby as someone who, having had formal chemistry training, had failed subsequently to make use of it in her life. She articulated a broad 
range of positions that might not sit well alongside the scientific account she was able to provide. For instance, during the home tour, she curled her lips in disgust when she talked about manipulating DNA, showing an important affective dimension to her situated reasoning. Gabby's scientific training did not "travel" alone when it came into contact with the rest of the world. This is much like Lave's (1988) cognition in practice where mathematics learned in the adult classroom does not "transfer" to the supermarket. In this regard, Gabby's position reminds us that classifications of "lay" and "expert" knowledge hide the complexity of people's understandings of science (Irwin and Michael 2003: 111); even people with formal scientific training can navigate everyday decisions using everyday logics.

In contrast to Jen's and Gabby's understandings of natural, in the culture of the laboratory the concern is not with "nature" in this everyday sense, but with the chemical "nature" of something: it's molecular arrangement, qualities, and the means of its creation. As Bensaude-Vincent and Newman (2007: 2) point out:

The recent products and future dreams of biotechnology and artificial intelligence present striking challenges to the commonsense distinction between the natural and the artificial. But in reality this distinction has always been confounded by human activities in the form of even the most primitive machines and technologies... The concept of nature functions and has always been used as a cultural value, a social norm, and a moral authority ... we cannot simply dismiss the distinction as "popular prejudice."

Thus, knowledge claims produced in scientific cultures may not fit easily into other contexts as they are reconstructed in cultures situated in homes and workplaces. The practices in which the everyday concept of nature is evoked cannot be supplanted with laboratory ones because it does not have the same moral authority in those contexts. Ethics of parenting and family trump the ethics of sustainability, economic development and so forth when it comes to rubbing ointments into children's skin. Our data and analyses show that in the face of scientific uncertainties, everyday cultural repertoires are put into action and frame how people imagine behaving in the future.

\section{Deference and Mediation}

This category refers to situations in which participants brought organizations or individuals into their talk about menthol or synthetic biology in order to manage their own sense of ignorance or uncertainty. In general, there has been a gradual decline in the deference shown to scientists when considering sociotechnical uncertainties (Nowotny et al. 2001). Nonetheless, in some engagements with participants we found that they were deferential to scientists and engineers, especially when it came to technical questions, but also to more emphatically ethical issues, such as whether or not biosynthetic menthol should be produced given some possible consequences. This often involved participants adopting a general depiction of scientists and engineers as being experts working in the public's best interests. This was most frequently seen in the pop-up stalls, for example, in the following postcard note: 
I agree with the long-term benefit [sustainability] versus short-term issues [farming job losses]. I am sure it would be safe. (female, 40s)

The participant above, like some others at the pop-up stalls, simply repeated back the claims of our synthetic biology colleagues regarding the promise of sustainability and the assurance of long-term economic benefit and biological safety. It may be that the pop-up stalls represent a form of engagement with science where people agree with the scientific reasoning in that context, and accept those conclusions, but return home and make sense of science using what is relevant to those mundane situations.

Deference to science did come up in the data, then, but what we more commonly observed were processes of mediation. Rather than simply accepting that scientists were responsible and that this meant participants could trust technical products, participants invoked other "closer" actors to mediate their relationship to scientific uncertainty or ignorance. This is because there was already a degree of ignorance and a related sense of uncertainty established in the use of menthol-containing products. As many such items contain a large number of ingredients, participants commonly expressed ignorance as to what was contained in the products they currently used, what the ingredients did or whether any of them were potentially harmful. As one participant put it, "I believe you would need a chemistry degree to understand what is on the back of these things most of the time." (Juliet, 35, home tour 2). Such uncertainty was managed through everyday practices of trust and relationships with trusted organizations, many of which were official regulatory bodies (e.g. people often invoked the idea of "regulators" or "standards agencies") but were just as frequently companies. Indeed, although both companies and regulatory bodies cultivate trust through branding, advertising, public relations, and so on for different reasons, participants rarely brought out specific differences between the two types of organization.

Trust was a key issue that many of our participants invoked when describing their current use of menthol-containing products, and when reasoning about a future in which biosynthetic menthol was a reality. Trust is perhaps best understood as "in-between" rational and irrational strategies for dealing with uncertainty (Zinn 2008, 2016). Many participants talked about trusting particular companies or brands of products, such as Vick's for vapor rub, as well as other societal actors. A familiarity with a brand builds trust and it is this social relationship between the role of "consumer" and "company" that is used to mediate uncertainties in science. In the following quotation, Gabby, 34, explains how she trusts the labeling and packaging systems that are on products she gives to her children:

Researcher: ... so, it wouldn't matter to you if you were putting menthol [derived] from a plant or a chemical process on you?

Gabby: To be [honest] it wouldn't matter, as long as it's [the product has] been through all the checks because... I personally would trust those things--as long as-if you know it says children can have it and that its safe for children, I am quite trust[ing]. I do check 
those [holding up products], like I say when they [my children] were little I did check to see if they can have it and use it and made sure I didn't give them anything-if it does say it then I would believe it. (Gabby, 34, home tour 3)

Gabby's response to the potential uncertainty in existing products enrolls other agencies: she refers the work of knowing whether something is safe or not for her children (in the cases of medicines and consumer goods, at least) to particular organizations. For Gabby, like several of our other participants, the complexity of modern products means that getting knowledge about each individual ingredient for all products would simply be impossible: trusting whilst acknowledging one's ignorance is a part of contemporary social life and people draw on their experiences and reflexive appreciation of their ignorance in deciding who and what to trust (Wynne 1996a,b). Gabby places her trust in various organizations, agencies and testing procedures that ensure that her chosen products are safe, but she doesn't know if these things are done properly, how they work exactly, and so forth. It is not in scientific knowledge that people are necessarily well-versed, but they are skillful at positioning their ignorance within the web of sociotechnical relations in which they are embroiled.

Some participants sought ethical mediation of the issues, for example in the following pop-up stall postcard comment, a participant wondered if it might be possible to involve the FairTrade organization to help ensure that farmers were protected as new biosynthetic products were developed:

Could you grow the bacteria in India? Ideally there'd be a middle ground, perhaps a fairtrade version could be developed? (Female, 40s)

Various forms of labeling, such as kite marks, were also used to negotiate such uncertainties. People used analyses by selected organizations as heuristics for making ethical decisions. For instance, Lara (35, Home tour 5) used Fair-Trade labeling when selecting some items, such as coffee and chocolate, but her product choices were also dependent on particular retailers. Kim (home tour 7) went into more detail about how she used the Vegan Society symbol to mediate unknowns. Kim was aware of her own ignorance of various everyday chemicals, and she referred the duty to be ethically knowledgeable to the Vegan Society. Similarly to Jen's point earlier, Kim argued that while it might be an ideal, researching every chemical is not compatible with practical configurations of everyday life. Thus, a Vegan symbol was a shorthand way to mediate uncertainty-the symbol satisfactorily certifies that a product meets specific ethical guidelines.

In these ways, participants drew in different actors and agents to deal with the uncertainty of the future in much the same way as they practically negotiate everyday practices. The uncertainty work commonly used to deal with everyday uncertainties regarding existing consumer products, placing trust in other actors and deference to scientific claims, were adapted to the possible futures in which biosynthetic menthol might become a reality. 


\section{Conclusion}

The paper contributes to the academic literature on uncertainty in two main areas. Whereas a lot of research in public engagement literature focuses on media and journalism, and therefore on the production and circulation of uncertainty, the argument presented above concentrates on the strategies people deploy to cope with their appreciation of uncertainty. Secondly, in the nuanced STS literature, uncertainties are predominantly considered in contexts of scientific work and governance. Our attention to everyday life, and mundane practices, adds to these discussions by developing an understanding of people's situated approaches to risk and unknowns through "everyday uncertainty work." Using sensory engagement methods we were able to show that how people go about dealing with uncertainty depends on the know-how, materials, aims and morals that are invoked, disrupted or displaced by particular expectations.

The attention to people's everyday uncertainty work highlights the importance of developing public understanding of science research towards deeper engagements in the everyday. Compared to the synbiophobiaphobia expressed by academic scientists as they imagine "the public," our data suggest a nuanced relationship between the history of GM and synthetic biology is developing. What we find is a complex, subtle negotiation of the competing forms of knowledge and non-knowledge that people hold, reflexively attuned to the situation in which they are being consulted about possible futures. Different kinds of elicitation practices therefore result in different kinds of interactions, with different forms of knowledge and nonknowledge becoming visible. Contrasts in the spaces in which interactions occurred, for example in the differences between a museum atrium and a family bathroom, connected to different practices and to different ways of interacting with us as researchers, for example as a teenager might participate in an engagement activity either in the role of a student doing her A-levels or as a youngest child and only girl in a large, working-class family. These contrasting spaces, practices, and roles activated different norms, morals, and principles and, crucially for our study, provided tools to support different ways of dealing with uncertainties. The implications for public engagement are powerful. Focusing on the strategies people use in understanding instead of on things like their "attitudes" creates possibilities for constructing alternative points of departure for the exploration and analysis of sociotechnical futures that are situated in the politics of everyday practice, in the home, work and play spaces of citizens, rather than being abstracted from them in workshops, dialogues, surveys and science cafes. What this study suggests, is that the specific strategies that people deploy in their everyday uncertainty work are likely to vary depending on the different practices that are entangled with particular sociotechnical presents and imagined futures. Consequently, there will not be a generic public approach to managing uncertainty in technoscience that can be discovered and changed in order to smooth innovation and commercialization. Rather, there are myriad routines that will be activated, adjusted, or created in people's everyday lives, to deal with uncertainties emerging from new consumer goods.

This suggests that social sciences (and perhaps sociology in particular) have a role to play in eliciting and interpreting people's everyday anticipatory strategies. Where further sociological innovation is required, is in representing such findings to decision makers in science and 
innovation, or for creating conditions where decision makers can experience the diversity of public sense-making, in order to govern from this perspective, rather than based on abstract, potentially misleading constructions developed in de-situated public engagement exercises.

\section{Author Biography}

Dr. Robert Meckin is a postdoctoral researcher in the Responsible Research and Innovation Group at the University of Manchester. He is interested in the mundane practices of bioscience among researcher communities and among publics and is experimenting with creative sociological methods in STS research. He also explores collaboration and interdisciplinarity and their co-production with knowledge in research. His $\mathrm{PhD}$ investigated how proponents of synthetic biology aligned academic science and engineering with other domains in society in material, organizational and rhetorical ways.

\section{Author Biography}

Dr. Andrew Balmer is Senior Lecturer in Sociology at the University of Manchester and member of the Morgan Centre for Research into Everyday Lives. His research explores a range of topics, including synthetic biology, lie detection, dementia, secrecy and lying. He is author of three books, including "Synthetic Biology: A Sociology of Changing Practices" with Palgrave Macmillan and "Lie Detection and the Law: Torture, Technology and Truth" with Routledge. He is currently an Editor of Sociology, a journal of the British Sociological Association.

\section{Acknowledgements}

The authors would like to thank our participants, our colleagues (especially Barbara Ribeiro and Phil Shapira), Lynne Chapman (formerly artist-in-residence in the Morgan Centre), the anonymous reviewers of this paper, and the editors for their helpful comments and suggestions. We also want to thank Awesome Walls Climbing Centers and Hulme Community Garden Centre for use of their facilities. The Manchester Synthetic Biology Research Centre for Fine and Specialty Chemicals (SYNBIOCHEM) is supported by the Biotechnology and Biological Sciences Research Council (award BB/M017702/1).

\section{References}

Adam, B. \& Groves, C. 2007. Future Matters: Action, Knowledge, Ethics, Leiden. Boston: Brill.

Akin, H., Rose, K., Scheufele, D., Simis-Wilkinson, M., Brossard, D., Xenos, M., \& Corley, E. 2017. "Mapping The Landscape of Public Attitudes on Synthetic Biology." BioScience 67 (3): 290-300. 
Balmer, A. \& Molyneux-Hodgson, S. 2013. "Bacterial Cultures: Ontologies of Bacteria and Engineering Expertise at the Nexus of Synthetic Biology and Water Services." Engineering Studies 5 (1): 59-73.

Balmer, A., Calvert, J., Marris, C., Molyneux-Hodgson, S., Frow, E., Kearnes, M., Bulpin, K., Schyfter, P., MacKenzie, A., \& Martin, P. 2015. “Taking Roles in Interdisciplinary Collaborations: Reflections on Working in Post-ELSI Spaces in the UK Synthetic Biology Community." Science and Technology Studies 28 (3): 3-25.

Bensaude-Vincent, B. \& Newman, W.R. 2007. "Introduction: The Artificial and the Natural: State of the Problem." In The Artificial and the Natural: An Evolving Polarity, edited by B. Bensaude-Vincent \& W. R. Newman, 1-20. Cambridge and London: The MIT Press.

Bergmann, K. 2002. Dealing with Consumer Uncertainty: Public Relations in the Food Sector, Berlin Heidelberg New York: Springer.

Bhattachary, D., Pascal Calitz, J. \& Hunter, A. 2010. Synthetic Biology Dialogue. London: TNSBRMB.

Bloor, M. 1978. "On the Analysis of Observational Data: A Discussion of the Worth and Uses of Inductive Techniques and Respondent Validation." Sociology 12: 545 - 557.

Bogner, A. 2012. The Paradox of Participation Experiments. Science, Technology, \& Human Values Technology and Human Values 37 (5): 506-527.

Borup, M., Brown, N., Konrad, K., \& van Lente, H. 2006. "The Sociology of Expectations in Science and Technology." Technology Analysis \& Strategic Management 18 (3-4): 285-298.

Böschen, S., Kastenhofer, K., Rust, I., Soentgen, J., \& Wehling, P. 2010. “Scientific Nonknowledge and its Political Dynamics: The Cases of Agri-Biotechnology and Mobile Phoning." Science, Technology, \& Human Values 35 (6): 783-811.

Braun, K. \& Kropp, C. 2010. "Beyond Speaking Truth? Institutional Responses to Uncertainty in Scientific Governance." Science, Technology \& Human Values 35 (6): 771-782

Brown, N., \& Kraft, A. 2006. "Blood Ties: Banking the Stem Cell Promise." Technology Analysis \& Strategic Management 18 (3-4): 313-27.

Brown, N., \& Michael, M. 2003. "A Sociology of Expectations: Retrospecting Prospects and Prospecting Retrospects." Technology Analysis \& Strategic Management 15 (1): 3-18.

Callon, M.L., Lascoumes, P.P. \& Barthe Y. 2009. Acting in an Uncertain World: An Essay on Technical Democracy. London: MIT Press.

Collins, L.C., \& Nerlich, B. 2016. "How Certain is "Certain"? Exploring how the EnglishLanguage Media Reported the Use of Calibrated Language in the Intergovernmental Panel on Climate Change's Fifth Assessment Report." Public Understanding of Science 25 (6): 656-673

Daston, L., \& Galison, P. 1992. The Image of Objectivity. Representations 40: 81-128.

Davies, S.R. 2018. “Characterizing Hacking: Mundane Engagement in US Hacker and Makerspaces*." Science, Technology \& Human Values 43 (2): 171-197.

De Leon, J.P. \& Cohen, J.H. 2005. "Object and Walking Probes in Ethnographic Interviewing." Field Methods, 1a7 (2): 200-204. 
Department for Education and Skills \& Qualifications and Curriculum Authority. 2004. Science: The National Curriculum for England. London.

Fox, R.C. 1957. "Chapter 2: Training for Uncertainty." In The Student-Physician: Introductory Studies in the Sociology of Medical Education edited by R.K. Merton, G. Reader, and P.L. Kendall, Patricia L. Cambridge, MA: Harvard University Press. pp. 207-241.

Fox, R.C. 2000. "Medical Uncertainty Revisited." In Handbook of Social Studies in Health and Medicine edited G.L Albrecht, R. Fitzpatrick, S.C. Scrimshaw. London: Sage.

Frow, E. 2017. From "Experiments of Concern" to "Groups of Concern." Science, Technology, E Human Values. http: / / journals.sagepub.com/ doi/10.1177/0162243917735382.

Horlick-Jones, T., Walls, J. \& Kitzinger, J. 2007. "Bricolage in Action: Learning About, Making Sense of, and Discussing, Issues About Genetically Modified Crops and Food." Health, Risk and Society. 9 (1): 83-103.

Jasanoff, S. 2011. Designs on Nature: Science and Democracy in Europe and the United States. Princeton, NJ: Princeton University Press.

Lawrence, B.M. 2007. Mint The Genus Mentha. Boca Raton: CRC Press.

Levidow, L. 1999. "Britain's Biotechnology Controversy: Elusive Science, Contested Expertise." New Genetics and Society. 18(1): 47-64.

Levidow, L. 2001. "Precautionary Uncertainty: Regulating GM Crops in Europe." Social Studies of Science. 31 (6): 842-874.

Lynch, M. 1998. "The Discursive Production of Uncertainty: The OJ Simpson Dream Team and the Sociology of Knowledge Machine." Social Studies of Science 28 (5-6): 829-868.

Marres, N. 2015. Material Participation: Technology, the Environment and Everyday Publics. Basingstoke and New York: Palgrave Macmillan.

Marres, N. \& Lezaun, J. 2011. "Materials and devices of the public: An introduction." Economy and Society 40 (4): 489-509.

Marris, C. 2015. "The Construction of Imaginaries of the Public as a Threat to Synthetic Biology." Science as Culture. 24 (1): 83-98.

Martin, E. 1994. Flexible Bodies: Tracking Immunity in American culture - From the Days of Polio to the Age of AIDs. Boston: Beacon Press.

Michael, M. 2012. "De-signing the object of sociology: Toward an "idiotic" methodology." Sociological Review. 60 (S1): 166-183.

Mollering, G. 2001. "The Nature of Trust: From Georg Simmel to a Theroy of Expectation, Interpretation and Suspension." Sociology 35 (2): 403-420.

Moreira, T., May, C., \& Bond, J. 2009. "Regulatory Objectivity in action: Mild Cognitive Impairment and the Collective Production of Uncertainty." Social Studies of Science 39 (5): 665-690.

Navid, E.L. \& Einsiedel, E.F. 2012. "Synthetic Biology in the Science Cafe: What Have We Learned About Public Engagement?" Journal of Science Communication 11 (4) A02.

Nowotny, H., P. Scott, and M. Gibbons. 2001. Re-thinking Science: Knowledge and the Public in an Age of Uncertainty. Cambridge: Polity Press.

Pallett, H. 2017. Synthetic Biology and Society Workshop Outputs. Norwich. 
Pauwels, E. 2013. “Public Understanding of Synthetic Biology." BioScience 63 (2): 79-89.

Petersen, I., Heinrichs, H., \& Peters, H.P. 2010. "Mass-mediated Expertise as Informal Policy Advice." Science, Technology, \& Human Values 35 (6): 865-887.

Pickersgill, M. 2011. "Ordering Disorder: Knowledge Production and Uncertainty in Neuroscience Research." Science as Culture 20 (1): 71-87.

Powell, M., Dunwoody, S., Griffin, R., \& Neuwirth, K. 2007. Exploring Lay Uncertainty About an Environmental Health Risk. Public Understanding of Science 16 (3): 323-343.

Rao, R. 2015. "Strategies in (-)-menthol synthesis." Chemistry LibreTexts. Available at: https: / / chem.libretexts.org/Textbook_Maps/Organic_Chemistry_Textbook_Maps/Map \%3A_Logic_of_Organic_Synthesis_(Rao)/06._Strategies_in_(-)-Menthol_Synthesis [Accessed March 6, 2018].

Ruhrmann, G., Guenther, L., Kessler, S. H., \& Milde, J. 2015. “Frames of Scientific Evidence: How Journalists Represent the (Un)Certainty of Molecular Medicine in Science Television Programs." Public Understanding of Science 24 (6): 681-696.

Ryghaug, M., Holtan Sørensen, K., \& Næss, R. 2011. Making Sense of Global Warming: Norwegians Appropriating Knowledge of Anthropogenic Climate Change. Public Understanding of Science 20 (6): 778-795.

Selin, C., Campbell Rawlings, K., de Ridder-Vignone, K., Sadowski, J., Altamirano Allende, C., Gano, G., Davies, S.R., \& Guston, D. 2017. “Experiments in Engagement: Designing Public Engagement with Science and Technology for Capacity Building." Public Understanding of Science 26 (6): 634-649.

Shackley, S., \& Wynne, B. 1996. "Representing Uncertainty in Global Climate Change Science and Policy: Boundary-Ordering Devices and Authority." Science, Technology, \& Human Values 21 (3): 275-302.

Silverman, D. 2014. Interpreting Qualitative Data: Methods for Analysing Talk, Text and Interaction. London: Sage.

Star, S.L. 1985. "Scientific Work and Uncertainty." Social Studies of Science 15 (3): 391-427.

Swidler, A. 2001. Talk of Love: How Culture Matters. Chicago and London: University of Chicago Press.

Timmermans, S., \& Angell, A. 2001. Evidence-Based Medicine, Clinical Uncertainty, and Learning to Doctor. Journal of Health and Social Behavior 42 (4): 342-359.

Toogood, H., Cheallaigh, A., Tait, S., Mansell, D., Jervis, A., Lygidakis, A., Humphreys, L., Takano, E., Gardiner, J., \& Scrutton, N. 2015. “Enzymatic Menthol Production: One-Pot Approach Using Engineered Escherichia coli." ACS Synthetic Biology 4 (10): 1112-1123.

Wainwright, S. P., Williams, C., Michael, M., Farsides, B., \& Cribb, A. 2006. "From Bench to Bedside? Biomedical Scientists' Expectations of Stem Cell Science as a Future Therapy for Diabetes." Social Science E Medicine 63 (8): 2052-64.

Woodward, S. 2016. "Object Interviews, Material Imaginings and "Unsettling" Methods: Interdisciplinary Approaches to Understanding Materials and Material Culture." Qualitative Research 16 (4): 359-374. 
Wynne, B. 1992. "Public Understanding of Science Research: New Horizons or Hall of Mirrors?" Public Understanding of Science 1: 37-43.

Wynne, B. 1992. "Uncertainty and Environmental Learning: Reconceiving Science and Policy in the Preventive Paradigm." Global Environmental Change 2 (2): 111-127.

Zinn, J.O. 2008. "Heading into the Unknown: Everyday Strategies for Managing Risk and Uncertainty." Health, Risk \& Society 10 (5): 439-50.

Zinn, J.O. 2016. “"In-between” and Other Reasonable Ways to Deal with Risk and Uncertainty: A Review Article." Health, Risk E Society 18 (7-8): 348-366. 